\title{
Efficient Plant Regeneration of Cymbidium aloifolium (L.) Sw., a Threatened Orchid of Nepal through Artificial Seed Technology
}

\author{
Shreeti Pradhan1, Babu Lal Tiruwa1, Bijay Raj Subedee², Bijaya Pant ${ }^{*}$ \\ ${ }^{1}$ Plant Biotechnology and Biochemistry Laboratory, Central Department of Botany, Tribhuvan University, Kirtipur, Kathmandu, Nepal \\ ${ }^{2}$ Research Centre for Applied Science and Technology, Tribhuvan University, Kirtipur, Kathmandu, Nepal \\ Email: ^bijayapant@gmail.com
}

How to cite this paper: Pradhan, S., Tiruwa, B.L., Subedee, B.R. and Pant, B. (2016) Efficient Plant Regeneration of Cymbidium aloifolium (L.) Sw., a Threatened Orchid of Nepal through Artificial Seed Technology. American Journal of Plant Sciences, 7, 19641974.

http://dx.doi.org/10.4236/ajps.2016.714179

Received: September 13, 2016

Accepted: October 9, 2016

Published: October 12, 2016

Copyright $\odot 2016$ by authors and Scientific Research Publishing Inc. This work is licensed under the Creative Commons Attribution International License (CC BY 4.0).

http://creativecommons.org/licenses/by/4.0/

(c) (i) Open Access

\begin{abstract}
Artificial seed technology is a method of considerable potential for mass propagation and conservation of rare, endangered and threatened species. In the present investigation, artificial seeds were obtained through encapsulation of three weeks old protocorm (3.0 $\pm 1.0 \mathrm{~mm}$ diameter) of Cymbidium aloifolium with calcium alginate. Artificial seeds were cultured on liquid Murashige and Skoog (MS) or Knudson (Kn C) medium at different strength $(\times 1.0,0.5,0.25)$ and full strength $(1.0)$ of both media supplemented with $0.5 \mathrm{mg} / \mathrm{l}$ 6-benzyl aminopurine (BAP) and $0.5 \mathrm{mg} / \mathrm{l} \alpha$-naphthalene acetic acid (NAA). Full strength of MS medium without plant growth regulators was found to be the most favourable condition for efficient plantlet regeneration of C. aloifolium (9.83 shoot and 2.66 roots per culture). The storage potential of artificial seed was tested at $4^{\circ} \mathrm{C}$ and room temperature $\left(\mathrm{RT}, 21^{\circ} \mathrm{C} \pm 2^{\circ} \mathrm{C}\right.$ ) for up to 90 days on both media and found $83.33 \%$ viability at $4^{\circ} \mathrm{C}$ storage on MS media. Eighty five percent of plantlets regenerated from artificial seeds culture were successfully hardened in a potting mixture of cocopeat, clay and sphagnum moss (2:1:1). Hence, the methodology can be used for propagation and conservation of $C$. aloifolium through artificial seed system.
\end{abstract}

\section{Keywords}

Artificial Seed, Protocorms, In Vitro, Germination, Encapsulation, Media

\section{Introduction}

Artificial seed technology involves the production of embryogenic or non-embryogenic regenerative explants enclosed in a protective capsule (coating) with the ultimate prod- 
uct behaving like a seed for many functions including germination and plant regeneration and establishment. The coating protects the explants from mechanical damage during handling and allows germination and conversion into seedling. Artificial seeds have also been referred to as Synthetic seed or Synseed. The concept of Synseed or Artificial seed was first propounded by Murashige in 1977 [1] which was later described by several other investigators due to a recent increase in research interest in Synseed technology [2]-[4]. Previously, the artificial seeds were largely developed by encapsulation of somatic embryo. However, the rate of production of uniform high quality embryo is lower in most species and as a result the preparation of efficient quality artificial seeds has been successful in only few crops like carrot and alfalfa [5]. Bapat et al. (1987) proposed the making of Synseed through the encapsulation of in vitro derived non-embryogenic propagules such as axillary meristems as in Morus indica [6]. This concept was successfully tested in a number of species subsequently [7]-[11].

Cymbidium aloifolium is one of the threatened epiphytic orchids of Nepal with medicinal and ornamental value [12] [13]. It has attractive long-lasting beautiful flowers making it an important floriculture species. $C$. aloifolium is now on the verge of extinction from its natural habitat due to deforestation, over exploitation for trade and absence of pollinators due to indiscriminate use of pesticides or other modifications of the biome [14]. Another reason for its decline is their slow germination rate in nature as they require specific mycorrhizal fungi for successful seed germination [15]. Hence, an efficient propagation strategy is required to save this threatened, economically important orchid. Tissue culture techniques have been widely used for the in vitro mass multiplication of several commercially important orchids. Nayak et al. (1997); Hossain et al. (2009); Nongdam and Chongtham (2011) and Pradhan et al. (2013) had already reported the in vitro multiplication of $C$. aloifolum by using different explants [16]-[19]. However, little is known about the artificial seed system for $C$. aloifolium. Artificial seeds technology, with its advantage of storage has enormous potential as a mass propagation system for $C$. aloifolium producing field-ready propagules. Therefore, the present investigation was aimed to develop a reliable protocol for production, short to mid-term storage and efficient regeneration of plantlets from artificial seeds containing protocorms of $C$. aloifolium. The present study is the further progress of our previous work in this orchid species [20]. This protocol could be useful for commercial propagation and $e x$-situ conservation of this species.

\section{Materials and Methods}

\subsection{Plant Material}

Three weeks old in vitro grown protocorms of Cymbidium aloifolium was used for the present investigation. Protocorms were obtained from in vitro germinated seeds of $C$. aloifolium. Seeds resided in a capsule; a single capsule contains many seeds. In order to produce protocorms, immature capsules of $C$. aloifolium, collected from the wild, were washed under running tap water for 20 minutes, agitated soaked and shaken in detergent water with two drops of tween 20 for 15 minutes and then washed with running 
tap water until all the detergent was removed. The capsules were then surface sterilized by dipping it in $70 \%$ alcohol for 2 minutes, followed by $1 \%$ sodium hypochlorite solution for 15 minutes. They were subsequently rinsed in sterile water for at least three times. The surface sterilized capsules were dried on filter paper under aseptic condition and cut longitudinally using a sterile sharp surgical blade to expose the seeds. Seeds were then inoculated on quarter (0.25), half (0.5) and full strength (1.0) of Murashige and Skoog (MS; Murashige and Skoog, 1962) [21] or Knudson (Kn C; Knudson, 1922) media [22] and full strength (1.0) of MS and Kn C media supplemented with $0.5 \mathrm{mg} / \mathrm{l}$ 6-benzyl aminopurine (BAP) and $0.5 \mathrm{mg} / \mathrm{l} \alpha$-naphthalene acetic acid (NAA). The cultures were maintained at $25^{\circ} \mathrm{C} \pm 2{ }^{\circ} \mathrm{C}$ under $16 / 8 \mathrm{~h}$ photoperiod from cool-white-light, giving 500 - 1000 lux at culture level. After ten weeks of culture, small green globular protocorms were formed. Three weeks after protocorms started appearing, they were ready for producing artificial seeds.

\subsection{Culture Medium and Incubation}

Murashige and Skoog (MS) and Knudson (Kn C) media were used as the basal medium for all in vitro germination and seedling development from artificial seed are reported here. MS medium is highly enriched with basal salts. It contains macronutrients, micronutrients, iron sources and vitamins however Knudson medium contains low concentration of similar components without vitamins. Both, MS \& Kn C liquid media [full (1.0), half (0.5) or quarter (0.25) strength] supplemented with or without plant growth regulators viz. BAP $(0.5 \mathrm{mg} / \mathrm{l})$ and NAA $(0.5 \mathrm{mg} / \mathrm{l})$ were used for this investigation. Basal medium were fortified with $30 \mathrm{~g} / \mathrm{l}$ sucrose and with or without different BAP \& NAA (Table 1). The $\mathrm{pH}$ of all media was adjusted to 5.8 using $0.1 \mathrm{~N} \mathrm{NaOH}$ or $\mathrm{HCl}$.

Table 1. Effect of MS \& Kn C liquid media on in-vitro germination and regeneration of plantlets from artificial seeds of Cymbidium aloifolium.

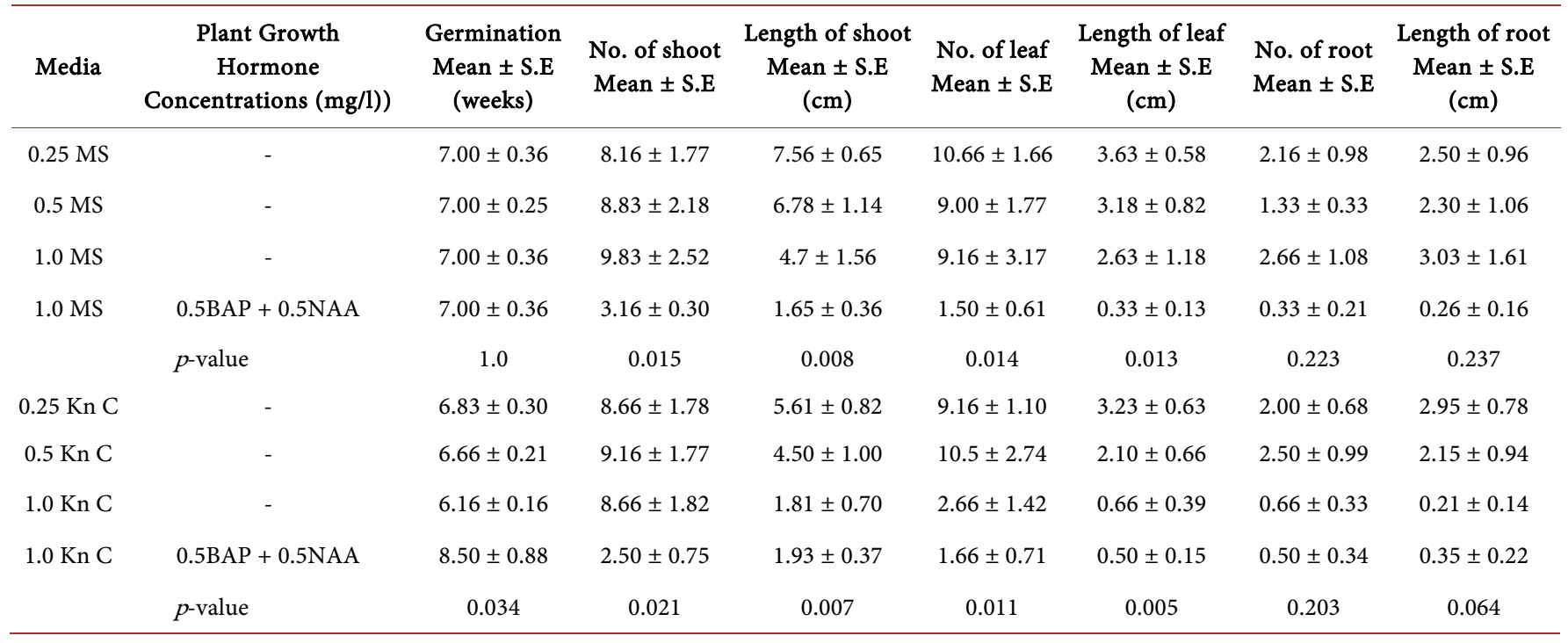

Culture conditions: -Various strength of MS \& Kn C liquid media, $25^{\circ} \mathrm{C} \pm 2^{\circ} \mathrm{C}, 24$ weeks, $16 / 8$ hrs. photoperiod, 6 replicates were used in each condition, $p$-values based on one-way ANOVA (df 3.23). 
About $20 \mathrm{ml}$ of medium was dispensed into each culture tube $(150 \times 25 \mathrm{~mm}$, Borosil) and autoclaved at $121^{\circ} \mathrm{C}$ for $20 \mathrm{~min}$ at $1.05 \mathrm{~kg} / \mathrm{cm}^{2}$ pressure. All cultures were maintained at $25^{\circ} \mathrm{C} \pm 2{ }^{\circ} \mathrm{C}$ under 500 - 1000 lux illuminance for $16 / 8 \mathrm{~h}$ (light/dark) photoperiod using cool white light (Philips, India).

\subsection{Encapsulation and Inoculation}

Artificial seeds were produced by encapsulation of three weeks old protocorms. Protocorms were mixed in the encapsulation matrix $[4 \%(\mathrm{w} / \mathrm{v})$ sodium alginate and calcium chloride dihydrate $\left(\mathrm{CaCl}_{2} \cdot 2 \mathrm{H}_{2} \mathrm{O}\right)$ solution $\left.(0.2 \mathrm{M})\right]$. Protocorms were drawn up with sodium alginate and dropped into $\mathrm{CaCl}_{2} \cdot 2 \mathrm{H}_{2} \mathrm{O}$ solution using a sterilized micropipette. The encapsulated protocorms were left in $\mathrm{CaCl}_{2} \cdot 2 \mathrm{H}_{2} \mathrm{O}$ solution for at least 30 minutes for hardening. Each bead contains a single protocorm. The beads, now on called artificial seeds, were washed with sterile water and then blotted dry in sterilized filter paper. Freshly prepared artificial seeds were inoculated on different experimental media for their germination and subsequent development (Table 1). The cultures were kept at $25^{\circ} \mathrm{C} \pm 2{ }^{\circ} \mathrm{C}$ under $16 / 8 \mathrm{~h}$ photoperiod from cool-white-light in culture room with $70 \%$ - $80 \%$ relative humidity depending upon the temperature. A set of 300 artificial seeds were kept in sterile petridish sealed with parafilm and stored at $4^{\circ} \mathrm{C}$ as well as at room temperature $\left(21^{\circ} \mathrm{C} \pm 2{ }^{\circ} \mathrm{C}\right)$ for 90 days. They were sampled monthly and inoculated in full strength liquid MS and $\mathrm{Kn} \mathrm{C}$ media for germination and plantlet development studies.

\subsection{Acclimatization}

Culture tubes containing rooted plants were opened and kept in the culture room for one week before transferring to greenhouse. Plantlets from the open culture vessels were removed, washed thoroughly with tap water, then dipped in $0.1 \%$ fungicide (Bavistin) solution for 5 minutes and washed with sterile water. They were then planted in earthen pots containing cocopeat, clay or sphagnum moss individually as well as in combination $(2: 1: 1 \mathrm{v} / \mathrm{v})$ for hardening. The potted plants were covered with a perforated plastic bag to maintain the humidity and kept under greenhouse until the seedlings were established. They were watered daily and fertilized with 5\% Hyponex solution (nitrogen, phosphorous and potassium in a ratio 20:10:10 were prepared in 100 $\mathrm{ml}$ ) and sprayed once a week. The acclimatized plants were observed regularly.

\subsection{Statistical Analysis}

The results are expressed as mean \pm SE of each treatment. There were 6 replicates per treatment and each experiment was repeated twice. Statistical analysis was carried out by using an analysis of variance (ANOVA) one way classification system. The data were analyzed by using application software-Micros of texcel. The significant difference between the medium and medium supplemented with different growth hormones were analysed at $P \leq 0.05$ using SPSS version 16.0 (SPSS Inc., USA). 


\section{Results}

In the present investigation, three weeks old protocorm were used as primary explants for production of artificial seeds. Though there are several gelling agents such as polyox, agar, agarose, alginate, carboxy methylcellulose, carrageenan, guar gum, etc. for artificial seed production; sodium alginate was selected as a gelling agent for this investigation because of its low toxicity, low cost, quick gellation and bio compatibility characteristics [23].

\subsection{Effect of Media on Regeneration of Plantlet from Artificial Seed}

Freshly produced artificial seeds through protocorms with mean size $3 \pm 1 \mathrm{~mm}$ in diameter were inoculated on liquid MS and Kn C media (full, half and quarter strength) with or without $0.5 \mathrm{mg} / \mathrm{l} \mathrm{BAP} \mathrm{\&} \mathrm{NAA} \mathrm{(Table} 1$ ). The initiation of artificial seed germination was started after 7 weeks of culture in all the concentrations of MS medium whereas in Kn C medium, germination of artificial seed occurred earlier, from 6-week onwards, on hormone-free full strength formulation.

Germinated artificial seeds developed into plantlets within 15 - 20 days of culture. From the observation (Table 1), it was found that maximum proliferation of shoot $(9.83 \pm 2.52)$ and root $(2.66 \pm 1.08)$ was found on hormone-free full strength MS medium followed by quarter strength MS. As germination was started at almost same time in all the tested conditions, the poorest development of shoot and root was observed on 1.0 MS medium supplemented with $0.5 \mathrm{mg} / \mathrm{l} \mathrm{BAP}$ and $0.5 \mathrm{mg} / \mathrm{l} \mathrm{NAA}$ than hormonefree medium. Leaf number and length of shoot and leaf were highest on 0.25 MS and 0.5 MS however; the time taken for their development was longer than hormone-free full strength MS media (data not shown). One way ANOVA showed that among the growth parameters studied only the number and length of shoot and leaf varied significantly among different conditions of MS medium ( $p<0.05$; Table 1$)$. In Kn C medium, the highest number of shoot $(9.16 \pm 1.77)$, leaf $(10.5 \pm 2.74)$ and roots $(2.50 \pm 0.99)$ were observed on $0.5 \mathrm{Kn} \mathrm{C}$ medium whereas maximum length of shoot $(5.61 \pm 0.82)$, leaf $(3.23 \pm 0.63)$ and roots $(2.95 \pm 0.78)$ were found on $0.25 \mathrm{Kn} \mathrm{C}$ medium (Table 1$)$. One way ANOVA showed that the value of all the growth parameters except number of root and length of root varied significantly among different conditions of $\mathrm{Kn} \mathrm{C}$ me$\operatorname{dium}(p<0.05$; Table 1$)$.

\subsection{Effect of Storage Conditions: Temperature and Duration for Viability}

In this investigation, the artificial seed of protocorm contained only calcium alginate and were devoid of any other nutrients or plant growth regulators. In both MS and Kn $\mathrm{C}$ media, artificial seeds stored at $4^{\circ} \mathrm{C}$ were green, fresh and remained intact inside the calcium alginate beads until 90 days; whereas those stored at RT became pale and reduced its size. In RT, artificial seeds ruptured slowly after 10 weeks of inoculation and most of them become contaminated; while at $4^{\circ} \mathrm{C}$ the germination was started within 7 - 8 weeks of inoculation on MS medium. In case of Kn C medium, stored artificial seeds 
germinated within 8 weeks of culture at $4^{\circ} \mathrm{C}$ and 10 - 11 weeks of culture at RT. On MS medium, $83.3 \%$ of artificial seeds stored for 30 days at $4^{\circ} \mathrm{C}$ were viable but it declined substantially with time. A similar trend was evident in $\mathrm{Kn} \mathrm{C}$ medium as well. On the other hand, the artificial seed of protocorm stored at RT showed only $30 \%$ viability on day 30 with no viability or regeneration after 60 days (Table 2).

\section{Discussions}

Artificial seeds offer many advantages and opportunities especially in cross pollinating species where seed production and germination is difficult and expensive [24]. Therefore, the present investigation was carried out for the purpose of germplasm storage, delivery and conservation of the threatened medicinal orchid Cymbidium aloifolium through artificial seeds. Both MS and Kn C media have been found suitable for artificial seed germination and regeneration of plantlets. The germination time of artificial seeds was found to be different with media and growth conditions.

Although all tested media were successfully supported the conversion of encapsulated protocorms into whole plantlet with shoot, leaf and root growth showed varied responses. It might be due to the compositional variation of two different media including plant hormones. Many shoot buds were regenerated directly from a single encapsulated protocorm which later developed into a whole plant (Figure 1(a) and Figure 1(b)). Though earlier germination was observed on hormone-free $\mathrm{Kn} \mathrm{C}$ medium, healthy and chlorophyllous shoots and roots were developed earlier on hormone free full strength of MS medium (Figure 1(c)). It could be due to the low amount of macro

Table 2. Effect of media, storage temperature and duration of storage on germination and plantlet development from artificial seeds of Cymbidium aloifolium.

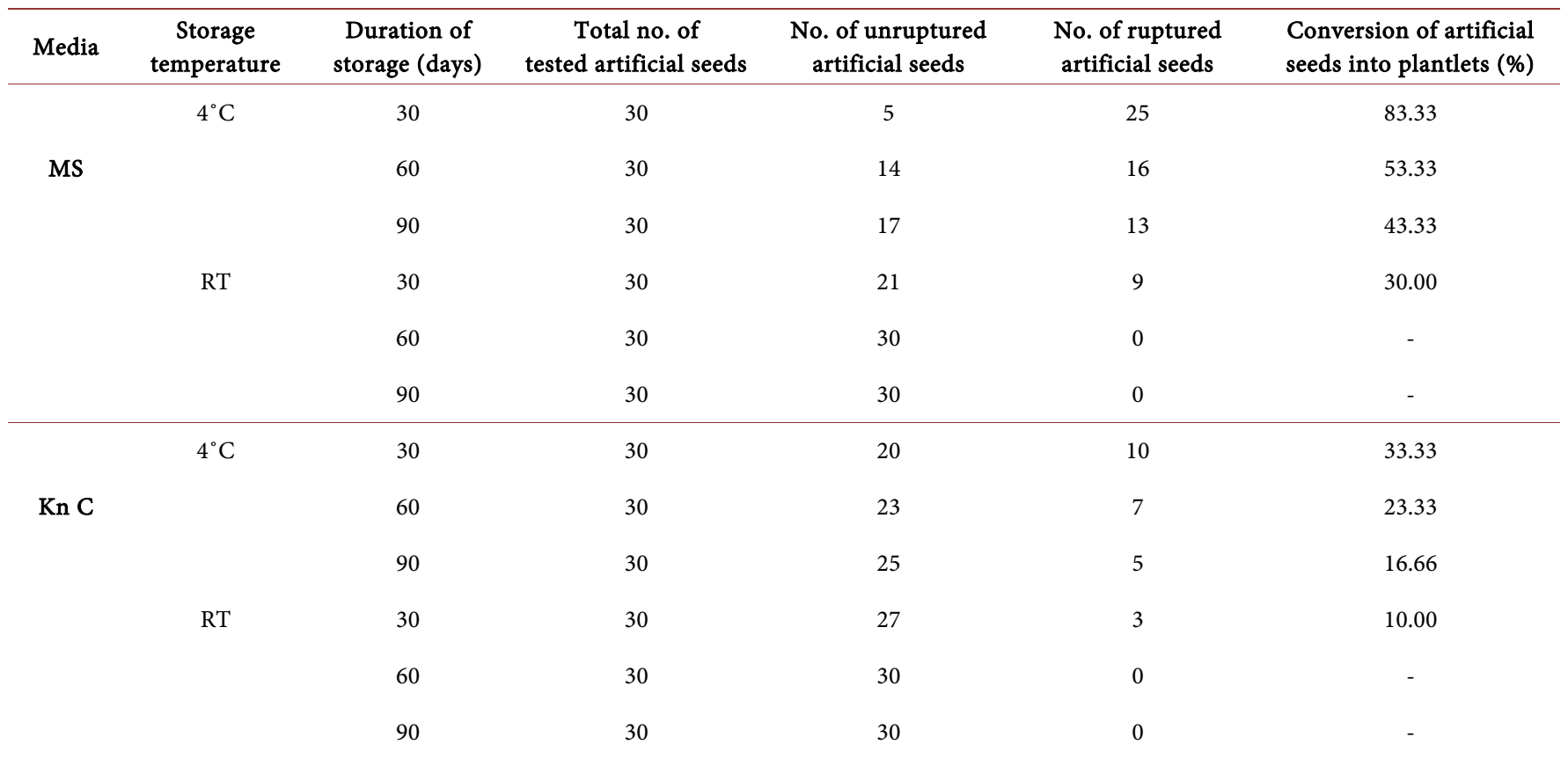

Culture conditions: MS \& Kn C liquid media, 90 days of storage, RT-room temperature $\left(21^{\circ} \mathrm{C} \pm 2^{\circ} \mathrm{C}\right)$. 


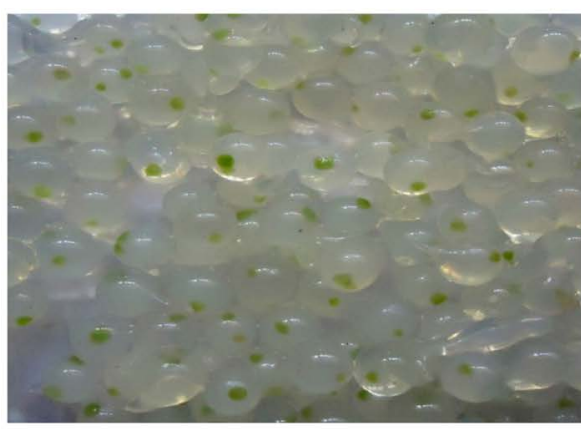

(a)

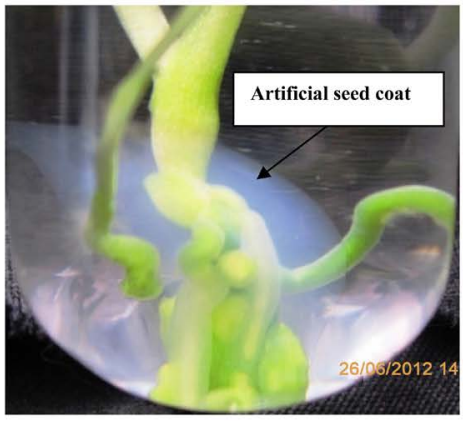

(c)

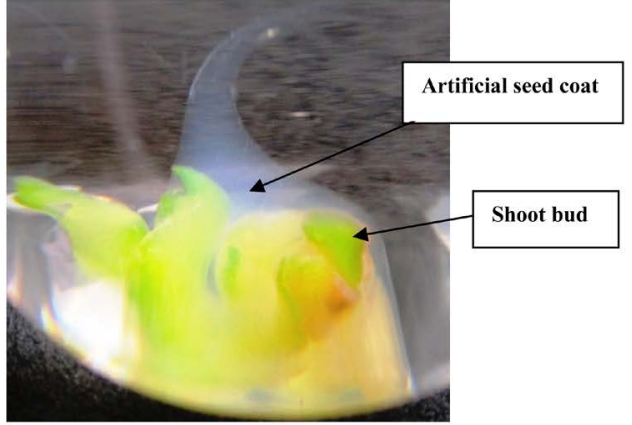

(b)

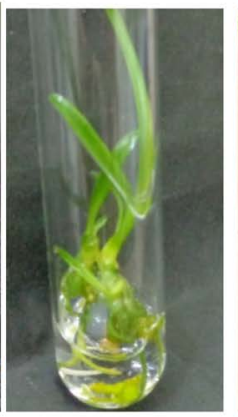

(d)

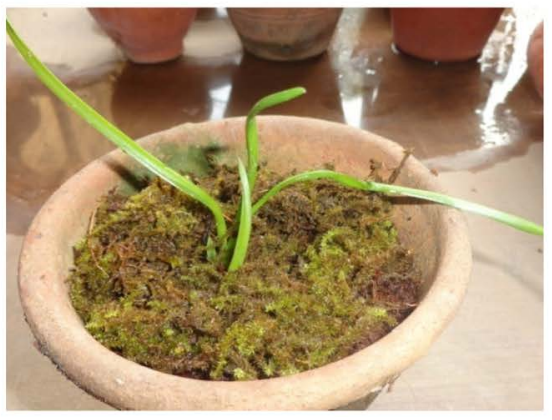

(e)

Figure 1. Production, germination and plantlet regeneration of artificial seed containing protocorms of Cymbidium aloifolium. (a) Production of artificial seed using 4\% sodium alginate and $0.2 \mathrm{M}$ calcium chloride solution; (b) Germinated artificial seeds gave rise to shoot bud on $0.25 \mathrm{MS}$ medium; (c) Development of healthy roots and shoot buds on hormone free 1.0 MS medium; (d) Multiplication of shoots with well developed roots on hormone free 1.0 MS medium; (e) Hardening of in vitro plantlets on potting mixture of cocopeat, clay and sphagnum moss of 2:1:1 ratio.

and micro nutrients present in $\mathrm{Kn} \mathrm{C}$ medium. Whereas MS medium was enriched with high concentration of nutritional compounds which made the suitability for efficient regeneration of healthy plantlet from artificial seed of Cymbidium aloifolium. Hence, MS medium was significantly more effective for germination and seedling development rather than $\mathrm{Kn} \mathrm{C}$ medium. In this medium, shoot buds were developed by cracking the alginate beads of artificial seeds of protocorms after 8 weeks of inoculation; complete plant with shoot and root were developed after 14 - 15 weeks of culture (Figure 1(d)). The most appropriate condition for the germination of the artificial seed was dependent on the time taken for germination, efficiency of germination, growth and development of seedlings. It can be concluded from this investigation that plants get physiologically stressed in hormone attributed both MS and $\mathrm{Kn} C$ media as a result they could not undergo proliferation sufficiently as much as like hormone free MS and Kn C media. In case of lower strength of MS media i.e. 0.25 MS \& 0.5 MS, plant didn't get sufficient nutrition as they required for their optimum development [19].

The present result was similar to the findings of other researchers: Gupta (2016) in Renanthera imschootiana [25], Teixeira da Silva (2012) in hybrid Cymbidium [26], 
Nagananda et al. (2011) in Flickingeria nodosa [27], Sarmah et al. (2010) in Vanda coerulea [28], Mohanraj et al. (2009) in Coelogyne breviscapa [15] in the aspect of production of artificial seed or Synseed from protocorm or protocorm like bodies for regeneration. However, the present findings are in contrast with the result obtained by other researchers in the aspect of culture of artificial seed in high concentration of hormone attributed medium. Zhang et al. (2011) reported that Maltose 4\%, 6-BA/NAA $12: 1$, active carbon $0.3 \%$, sodium alginate $4 \%$ and time of ion exchange for 5 minutes were optimum condition for artificial seed production with PLB's in Dendrobium candidum [29]. As well, Qin et al. (2008) found that modified MS with 4\% maltose and BA $(1 \mathrm{mg} / \mathrm{l})$ and NAA $(1 \mathrm{mg} / \mathrm{l})$ favoured germination and seedling of orchid Dendrobium huoshanesises by using 4\% sodium alginate [30]. Moreover, Datta et al. (1999) found that modified Knudson medium supplemented with BAP (1 mg/l) and NAA (1 mg/l) was the most effective condition for germination of artificial seed of Geodorum densiflorum (Lan) Schltr. [5]. Further, Saiprasad and Polisetty (2003) reported 100\% conversion of encapsulated PLBs when cultured on MS medium supplemented with BA (4.44 $\mu \mathrm{M})$ and NAA $(0.54 \mu \mathrm{M})$ on Dendrobium and NAA alone on Oncidium and Cattleya [31]. Finally, Mohanty and Das (2013) found that MS medium supplemented with 2 $\mathrm{mg} / \mathrm{l}$ BAP was efficient for $100 \%$ conversion of encapsulated PLB's into plantlets on Dendrobium densiflorum Lindl. ex Wall. [32].

Besides germination and mass propagation of artificial seeds containing protocorms of Cymbidium aloifolium, the viability of stored artificial seeds were observed until 90 days in two different temperatures i.e. room temperature (RT, $21^{\circ} \mathrm{C} \pm 2{ }^{\circ} \mathrm{C}$ ) and $4^{\circ} \mathrm{C}$. In both media, it was found that the viability percentage of artificial seeds of protocorms decreased gradually with increase in storage time. The decline in germination and plant development as a result of prolonged storage of tissue could be due to the inhibited respiration of tissues [32] [33]. The maximum percentage of viability was observed in 30 days stored artificial seed $(83.33 \%)$ at $4^{\circ} \mathrm{C}$ inoculated on MS medium. This result revealed that the germination and regeneration capacity of the stored artificial seeds at $4^{\circ} \mathrm{C}$ was quite higher rather than stored at RT. It might be due to the chilling effect of low temperature, which not only store the calcium alginate beads for prolonged period by reducing their growth but also enhance its regeneration capacity when transferred to re-growth medium containing essential nutrients. Here, the storage temperature and duration of storage were played an important role on conversion of artificial seeds into plantlets (Table 2). The present result was supported by the findings obtained by various researchers: Pradhan et al. (2014) successfully stored the artificial seed of Cymbidium aloifolium up to 28 days on MS medium with $97.5 \%$ conversion rate [20]. Nagananda et al. (2011) encapsulated the PLBs of Flickingeria nodosa and achieved 95\% conversion after 3 months storage at $4^{\circ} \mathrm{C}$ [27]. Zhang et al. (2011) produced artificial seeds of Dendrobium candidum with protocormlike bodies as propagator and achieved the germination rate $87.70 \pm 0.46$ after 5 days and $14.87 \pm 0.31$ after 20 days of storage in refrigerator at $4^{\circ} \mathrm{C}$ which was lower compared to the present investigation [29]. Similarly, Datta et al. (1999) found 86\% viability of artificial seeds of Geodorum densi- 
florum when stored at $4^{\circ} \mathrm{C}$ and $44 \%$ viability when stored at room temperature for 120 days. Nutrient medium also plays a crucial role on germination and development of artificial seed [5]. In present investigation, MS medium was found to be the most favourable condition for regeneration of plantlet from fresh as well as stored artificial seed containing protocoms of $C$. aloifolium. The use of MS medium only for regeneration of plantlet from stored artificial seed also provides a way to reduce the costs by eliminating the need for plant hormones.

The ultimate objective of producing artificial seed was to recover the whole plantlet from artificial seed under in vitro condition. In present investigation, in vitro plant with well-developed roots obtained from artificial seeds, cultured on both MS and Kn C media after attaining the height of $4-5 \mathrm{~cm}$ was selected for acclimatization. They were transferred to earthen pot containing different acclimatization substrates. The combination of cocopeat, clay and sphagnum moss in ratio 2:1:1 was found to be a suitable potting mixture for hardening (Figure 1(e)). Eighty five percentage of seedlings were successfully survived under this condition. Hence, this result suggests that the mixture of cocopeat, clay and moss will be favourable for the acclimatization of epiphytic orchids as in Cymbidium aloifolium.

\section{Conclusion}

Many researchers have successfully produced and propagated artificial seed of many crops but very limited in orchids. The present investigation revealed that full strength of liquid MS medium without plant growth regulators was found to be the most effective condition for germination as well as for development of efficient plant regeneration from artificial seeds of Cymbidium aloifolium than other tested conditions of MS and $\mathrm{Kn} \mathrm{C}$ medium. 30 days stored artificial seeds have showed highest percentage of viability i.e. $83.33 \%$ at $4^{\circ} \mathrm{C}$ on MS medium as compared to 60 and 90 days of storage. The development of protocol for direct recovery of plant from artificial seeds may have greater impact on tissue culture methods. Therefore, the present investigation concluded that artificial seeds have the excellent potential to be used as alternative planting materials for in vitro clonal mass multiplication, short to medium term storage, easy handling and transportation and ex-situ conservation of economically important species like Cymbidium aloifolium. Hence, the protocol established from present investigation can be employed for large scale propagation of $C$. aloifolium which may be not only useful for fulfilling the urgent local needs for effective conservation but also reliable for plant breeders and local orchid growers for storage of plant genetic resources, easy delivery and their commercial production by using minimum space with lower labour and maintenance cost.

\section{Acknowledgements}

Authors are grateful to Central Department of Botany, Tribhuvan University, Kirtipur, Nepal for providing all laboratory facilities for this investigation. We are also thankful to Nepal Academy of Science and Technology (NAST), Khumaltar, Lalitpur, Nepal for providing the financial assistance to carry out the present research work. 


\section{References}

[1] Murashige, T. (1977) Plant Cell and Organ Cultures as Horticultural Practices. Symposium on Tissue Culture for Horticultural Purposes, 78, 17-30.

http://dx.doi.org/10.17660/actahortic.1977.78.1

[2] Lambardi, M., Benelli, C., Ozudogru, E.A. and Ozden-Tokatli, Y. (2006) Synthetic Seed Technology in Ornamental Plants. Floriculture, Ornamental and Plant Biotechnology: Advances and Topical Issues, 2, 347-354.

[3] Asmah, H.N., Hasnida, H.N., Zaimah, N.N., Noraliza, A. and Salmi, N.N. (2011) Synthetic Seed Technology for Encapsulation and Regrowth of In Vitro-Derived Acacia Hyrid Shoot and Axillary Buds. African Journal of Biotechnology, 10, 7820-7824.

http://dx.doi.org/10.5897/AJB11.492

[4] Reddy, M.C., Murthy, K.S.R. and Pullaiah, T. (2012) Synthetic Seeds: A Review in Agriculture and Forestry. African Journal of Biotechnology, 11, 14254-14275.

[5] Datta, K.B., Kanjilal, B. and De Sarker, D. (1999) Artificial Seed Technology: Development of a Protocol in Geodorum densiflorum (Lam) Schltr.-An Endangered Orchid. Current Science, 76, 1142-1145.

[6] Bapat, V.A., Mhatre, M. and Rao, P.S. (1987) Propagation of Morusindica L. (Mulberry) by Encapsulated Shoot Buds. Plant Cell Reports, 6, 393-395.

http://dx.doi.org/10.1007/BF00269570

[7] Singh, F. (1991) Encapsulation of Spathoglottis plicata Protocorms. Lindleyana, 6, 61-63.

[8] Corrie, S. and Tandon, P. (1993) Propagation of Cymbidium giganteum Wall, through high Frequency Conversion of Encapsulated Protocorms under In Vivo and In Vitro Conditions. Indian Journal of Experimental Biology, 31, 61-64.

[9] Piccioni, E. and Standardi, A. (1995) Encapsulation of Micropropagated Buds of Six Woody Species. Plant Cell, Tissue and Organ Culture, 42, 221-226.

http://dx.doi.org/10.1007/BF00029990

[10] Chen, D.F., Chen, X.W. and Li, Z.D. (1996) Germination and Storage Characteristics of Ramie Artificial Seeds Made of Adventitious Buds. China's Fibre Crops, 2, 1-5.

[11] Yoshida, T. (1996) In Vitro Propagation of Hybrid Rice (Oryzasativa L.) 1. "Tissue Cultured" Shoot Primordia. Japan Agricultural Research Quarterly, 30, 1-8.

[12] Das, P.K., Sahoo, S. and Bal, S. (2008) Ethnobotanical Studies on Orchids of Niyamgiri Hill Ranges, Orissa, India. Ethnobotanical Leaflets, 12, 70-78.

[13] Pant, B. and Raskoti, B.B. (2013) Medicinal Orchids of Nepal. Himalayan Map House Pvt. Ltd., Nepal.

[14] Chugh, S., Guha, S. and Rao, I.U. (2009) Micropropagation of Orchids: A Review on the Potential of Different Explants. Scientia Horticulturae, 122, 507-520. http://dx.doi.org/10.1016/j.scienta.2009.07.016

[15] Mohanraj, R., Ananthan, R. and Bai, V.N. (2009) Production and Storage of Synthetic Seeds in Coelogyne breviscapa Lindl. Asian Journal of Biotechnology, 1, 124-128. http://dx.doi.org/10.3923/ajbkr.2009.124.128

[16] Nayak, N.R., Rath, S.P. and Patnaik, S. (1997) In Vitro Propagation of Three Epiphytic Orchids, Cymbidium aloifolium (L.) Sw., Dendrobium aphyllum (Roxb.) Fisch. and Dendrobium moschatum (Buch-Ham) Sw. through Thidiazuron-Induced High Frequency Shoot Proliferation. Scientia Horticulturae, 71, 243-250. http://dx.doi.org/10.1016/S0304-4238(97)00075-7

[17] Hossain, M.M., Sharma, M. and Pathak, P. (2009) Cost Effective Protocol for in Vitro Mass 
Propagation of Cymbidium aloifolium (L.) Sw.-A Medicinally Important Orchid. Engineering in Life Sciences, 9, 444-453. http://dx.doi.org/10.1002/elsc.200900015

[18] Nongdam, P. and Chongtham, N. (2011) In Vitro Rapid Propagation of Cymbidium aloifolium (L.) Sw.: A Medicinally Important Orchid via Seed Culture. Journal of Biological Sciences, 11, 254-260. http://dx.doi.org/10.3923/jbs.2011.254.260

[19] Pradhan, S., Regmi, T., Parmar, G. and Pant, B. (2013) Effect of Different Media on in Vitro Seed Germination and Seedling Development of Cymbidium aloifolium (L.) Sw. Nepal Journal of Science and Technology, 14, 51-56. http://dx.doi.org/10.3126/njst.v14i1.8878

[20] Pradhan, S., Tiruwa, B., Subedee, B.R. and Pant, B. (2014) In Vitro Germination and Propagation of a Threatened Medicinal Orchid, Cymbidium aloifolium (L.) Sw. through Artificial Seed. Asian Pacific Journal of Tropical Biomedicine, 4, 971-976. http://dx.doi.org/10.12980/APJTB.4.2014APJTB-2014-0369

[21] Murashige, T. and Skoog, F. (1962) A Revised Medium for Rapid Growth and Bio Assays with Tobacco Tissue Cultures. Physiologiaplantarum, 15, 473-497. http://dx.doi.org/10.1111/j.1399-3054.1962.tb08052.x

[22] Knudson, L. (1922) Non Symbiotic Germination of Orchid Seeds. Botanical Gazette, 73, 125. http://dx.doi.org/10.1086/332956

[23] Saiprasad, G.V.S. (2001) Artificial Seeds and Their Applications. Resonance, 6, 39-47. http://dx.doi.org/10.1007/BF02839082

[24] Latif, Z., Idrees, A., Nasir, A. and Riazuddin S. (2007) Indigenous Production of Synthetic Seeds in Daucus carota. Pakistan Journal of Botany, 39, 849-855.

[25] Gupta, A. (2016) Regeneration of Renanthera imschootiana Rolfe Using Synthetic Seeds. International Advanced Research Journal in Science, Engineering and Technology, 3, 286289.

[26] Teixeira da Silva, J.A. (2012) Production of Synseed for Hybrid Cymbidium Using Protocorm-Like Bodies. Journal of Fruit and Ornamental Plant Research, 20, 135-146. http://dx.doi.org/10.2478/v10290-012-0023-7

[27] Nagananda, G.S., Satishchandra, N. and Rajath, S. (2011) Regeneration of Encapsulated Protocormlike Bodies of Medicinally Important Vulnerable Orchid Flickingeria nodosa (Dalz.) Seidenf. International Journal of Botany, 7, 310-313. http://dx.doi.org/10.3923/ijb.2011.310.313

[28] Sarmah, D.K., Borthakur, M. and Borua, P.K. (2010) Artificial Seed Production from Encapsulated PLBs Regenerated from Leaf Base of Vanda coerulea Grifft. ex. Lindl._An Endangered Orchid. Current Science, 98, 686-690.

[29] Zhang, Y., Yan, S. and Zhang, Y. (2011) Factors Affecting Germination and Propagators of Artificial Seeds of Dendrobium candidum. International Conference on Agricultural and Biosystems Engineering, Paris, 24-26 June 2011, 404-410.

[30] Qin, Z., Zhao, T., Qiu, J., Lin, Y. and Cai, Y. (2008). Germination and Propagartors of Artificial Seeds of Dendrobium huoshanense. Chinese Journal of Biotechnology, 24, 803-809.

[31] Saiprasad, G.V.S. and Polisetty, R. (2003) Propagation of Three Orchid Genera Using Encapsulated Protocorm-Like Bodies. In Vitro Cellular \& Developmental Biology-Plant, 39, 42-48. http://dx.doi.org/10.1079/IVP2002360

[32] Mohanty, P. and Das, J. (2013) Synthetic Seed Technology for Short Term Conservation of Medicinal Orchid Dendrobium densiflorum Lindl. Ex Wall and Assessment of Genetic Fidelity of Regenerants. Plant Growth Regulation, 70, 297-303.

http://dx.doi.org/10.1007/s10725-013-9801-z

[33] Danso, K.E. and Ford-Lloyd, B.V. (2003) Encapsulation of Nodal Cuttings and Shoot Tips for Storage and Exchange of Cassava Germplasm. Plant Cell Reports, 21, 718-725. 
Submit or recommend next manuscript to SCIRP and we will provide best service for you:

Accepting pre-submission inquiries through Email, Facebook, LinkedIn, Twitter, etc.

A wide selection of journals (inclusive of 9 subjects, more than 200 journals)

Providing 24-hour high-quality service

User-friendly online submission system

Fair and swift peer-review system

Efficient typesetting and proofreading procedure

Display of the result of downloads and visits, as well as the number of cited articles

Maximum dissemination of your research work

Submit your manuscript at: http://papersubmission.scirp.org/

Or contact ajps@scirp.org 